\title{
COMPOSIÇÃO CENTESIMAL, LISINA DISPONÍVEL E DIGESTIBILIDADE IN VITRO DE PROTEÍNAS DE FÓRMULAS PARA NUTRIÇÃO ORAL OU ENTERAL ${ }^{1}$
}

\author{
Edma M. ARAÚJO², Hilary C. MENEZES ${ }^{2 *}$
}

\begin{abstract}
RESUMO
Ultimamente tem-se verificado aumento do uso de nutrição enteral (NE) em domicílio, objetivando reduzir custos e melhorar a qualidade de vida. Contudo, é importante monitorar o valor nutricional das dietas. Nesse estudo foram avaliadas as formulações F1 e F2 (ARAÚJO; GALEAZZI, 1999) contendo carne bovina, ovo (F1), chicória, cenoura, fubá de milho, extrato hidrossolúvel de soja, óleo de soja, Nidex $^{\circledast}$ e sal, para uso em NE ou oral domiciliar, objetivando obter dados mais confiáveis e seguros. Foram determinadas: composição centesimal, digestibilidade in vitro e lisina disponível. As composições centesimais (base seca) foram as seguintes: F1: calorias 454,69, umidade $79,29 \pm 0,07$, proteína $17,04 \pm 0,06$, lipídios $14,85 \pm 0,11$, carboidratos 63,22 , fibra alimentar solúvel 0,67 $\pm 0,66$ e insolúvel $1,65 \pm 0,73$, cinzas $2,57 \pm 0,01 ; \mathrm{F} 2$ : calorias 463,92 , umidade $78,96 \pm 0,09$, proteína $16,56 \pm 0,09$, lipídios $15,12 \pm 0,20$, fibra alimentar solúvel $1,09 \pm 0,11$ e insolúvel $1,84 \pm 0,09$, carboidratos 65,40 e cinzas $2,63 \pm 0,08$. A distribuição calórica mostrou-se adequada. Os teores de lisina eram $80 \mathrm{mg} / \mathrm{g}$ de proteína para $\mathrm{F} 1$ e 139 para F2. A digestibilidade (\%) das proteínas foi 95 para $\mathrm{F} 1$ e 93 para F2. As formulações são factíveis de preparo em domicílio, possuem fontes de proteína de boa qualidade, baixo custo, podendo atender às necessidades nutricionais de indivíduos em terapia nutricional domiciliar e promover a recuperação nutricional.

Palavras chave: qualidade protéica, alimentação enteral domiciliar, suplemento oral, valor nutricional, formulações.
\end{abstract}

\section{SUMMARY}

PROXIMATE COMPOSITION, AVAILABLE LYSINE AND IN VITRO DIGESTIBILITY OF PROTEINS IN FORMULAE FOR ORAL OR ENTERAL NUTRITION. Recently the use of home enteral nutrition (EN) has increased, aimed at reducing costs and improving the quality of life. Monitoring the nutritional value of these diets is therefore important. In this study the formulations F1 and F2 (ARAÚJO; GALEAZZI, 1999) containing beef, egg (F1), chicory, carrot, corn grits, water-soluble soybean extract, soybean oil, Nidex ${ }^{\mathbb{8}}$ and salt, were evaluated for use in home EN, aiming at obtaining more reliable, safer data. The following were determined: proximate composition, in vitro digestibility and available lysine. The proximate compositions (dwb) of the formulations were: F1: $454.69 \mathrm{Kcal}$, moisture $79.29 \pm 0.07$, protein $17.04 \pm 0.06$, lipids $14.85 \pm 0.11$, carbohydrates 63.22 , soluble $0.67 \pm 0.66$ and insoluble $1.65 \pm 0.73$ fiber and ash $2.57 \pm 0.01$; F2: 463.92Kcal, moisture 78.96 \pm 0.09 , protein $16.56 \pm 0.09$, lipids $15.12 \pm 0.20$, soluble $1.09 \pm 0.11$ and insoluble $1.84 \pm 0.09$ fiber, carbohydrates 65.40 and ash $2.63 \pm 0.08$. The caloric distribution was shown to be adequate. The lysine contents in $\mathrm{mg} / \mathrm{g}$ of protein were 80 for F1 and 139 for $\mathrm{F} 2$ and \% protein digestibility was $95 \%$ for $\mathrm{F} 1$ and $93 \%$ for $\mathrm{F} 2$. The formulations were adequate for domestic preparation and contained good quality, low cost protein sources, capable of attending the nutritional requirements of individuals using home EN, promoting nutritional recovery.

Keywords: protein quality, home enteral nutrition, oral supplement, nutritional value, formulations.

\section{1 - INTRODUÇÃO}

Tem-se verificado um crescente aumento do uso de nutrição enteral (NE) em terapia domiciliar. Quando em ambiente domiciliar, o suporte nutricional objetiva não só humanizar o atendimento aos pacientes, como também melhorar ou manter o estado nutricional, além de colaborar para a maior disponibilidade de leitos hospitalares e de reduzir os custos do tratamento.

As formulações enterais continuam a fazer parte do esquema alimentar domiciliar de pacientes de baixa renda $[12,13]$. As dietas enterais elaboradas com alimentos convencionais (AC), combinadas ou não com dietas industrializadas, permitem a extensão desse tipo de terapia às classes mais baixas da sociedade, bem como obter uma individualização da dieta nos casos em que as necessidades de alguns pacientes não são satisfeitas por uma fórmula padrão. No entanto, é importante monitorar o valor nutricional deste tipo de dieta para obter maior segurança na

\footnotetext{
${ }^{1}$ Recebido para publicação em 24/01/2005. Aceito para publicação em 03/09/2005 (001472).

${ }^{2}$ Núcleo de Estudos e Pesquisas em Alimentação - NEPA/UNICAMP

Rua Albert Einstein, 291 - 13083-970 Campinas, SP - Brasil. E-mail: nepa@unicamp.br.

* A quem a correspondência deve ser enviada.
}

ingestão de nutrientes [9]. No Brasil, os dados das tabelas de composição de alimentos são pouco confiáveis por estarem desatualizados e por falta de descrição dos procedimentos analíticos e dos critérios de amostragem, entre outros. Há, portanto, dados de qualidades variáveis que não oferecem segurança para utilização em nutrição clínica.

Com o objetivo de obter formulações com valor nutricional mais confiável, foram desenvolvidas duas formulações [2], denominadas F1 e F2, para uso em nutrição oral ou enteral, factíveis de preparo em domicílio, com AC de baixo custo, fácil aquisição e disponíveis nas regiões menos desenvolvidas ou distantes dos grandes centros comerciais onde as dietas industrializadas não são comercializadas. No presente trabalho, o objetivo foi determinar a composição centesimal, o teor de lisina disponível e a digestibilidade in vitro das proteínas das formulações.

\section{2 - MATERIAL E MÉTODOS}

\section{1 - Formulações F1 e F2 [2] desenvolvidas no NEPA/UNICAMP}

Alimentos: carne bovina (coxão mole sem gordura e sem aponevrose), ovo (F1) vermelho tamanho médio, chicória (Cichorium endivia L.), cenoura (Daucus carota L.), 
fubá de milho amarelo tipo mimoso, extrato hidrossolúvel de soja (EHS), óleo de soja, complemento energético (CE) $\mathrm{Nidex}^{\circledR}$, sal. Os alimentos foram adquiridos (em triplicata) no comércio de Campinas, SP. Todos os alimentos foram pesados em balança analítica (Scientech SA 120, Tecnal ${ }^{\circledR}$, Brasil).

\begin{tabular}{lcc} 
TABELA $\mathbf{1}$ - Quantidades de alimentos para 2 L de dieta \\
\hline Alimentos (g) & F1 $^{\mathbf{1}}$ & F2 $^{\mathbf{2}}$ \\
\hline Fubá de milho & 80 & 80 \\
Complemento energético Nidex & 185 & 185 \\
Carne bovina & 200 & 200 \\
Ovo & 50 & - \\
Extrato hidrossolúvel de soja & 70 & 75 \\
Cenoura & 50 & 50 \\
Chicória & 100 & 100 \\
Óleo de soja & 40 & 45 \\
Sal iodado & 3 & 4
\end{tabular}

${ }^{2} \mathrm{~F} 1 \mathrm{e}^{2} \mathrm{~F} 2$ : formuladas no NEPA

Fórmula F1: com três fontes de proteína, duas fontes animais (carne, ovo) e uma fonte vegetal (EHS)

Fórmula F2: com duas fontes de proteína, uma animal (carne) e uma vegetal (EHS)

\section{2 - Preparação das amostras}

As amostras foram preparadas em laboratório (ambiente similar a um domicílio) em panela de pressão (12 psi, cap. 4 L, Clock ${ }^{\circledR}$, Brasil). Os alimentos foram cortados em pedaços pequenos, colocados em água fria (2L) e levados à cocção em fogo baixo durante duas horas e dez minutos. Após cocção, a preparação foi triturada e homogeneizada em liquidificador (M-Pic-Liq, Arno ${ }^{\circledR}$, São Paulo, Brasil), peneirada (tela de nylon plana, aberturas de $1 \mathrm{~mm}$ de diâmetro), congelada e liofilizada para as análises.

\section{3 - Composição centesimal}

Análises químicas: a proteína foi quantificada pelo método de semimicro KJeldahl [4], sendo a conversão do nitrogênio total em proteína bruta pelo fator 6,25; lipídios totais segundo procedimento descrito por BLIGH \& DYER [6], (homogeneizador, AP-22, Tecnal ${ }^{\circledR}$, Piracicaba, Brasil); fibra alimentar solúvel e insolúvel pelo método enzimático [3] (banho metabólico com agitação reciprocante, tipo Dubnoff, MA-093, Marconi ${ }^{\circledR}$, Piracicaba, Brasil); teor de cinzas pelo método de incineração em mufla (EDGCON 1P, EDG Equipamentos ${ }^{\circledR}$, São Paulo, Brasil) a $550^{\circ} \mathrm{C}$ e de umidade, amostras integrais, em estufa (M-315 SE, Fanem ${ }^{\circledR}$, São Paulo, Brasil) $105^{\circ} \mathrm{C}$, até peso constante [10]. As análises foram realizadas em triplicata. Os carboidratos totais foram estimados por diferença, diminuindo-se de 100 a somatória de proteínas, lipídios, cinzas, umidade e fibra alimentar solúvel e insolúvel. Os resultados foram expressos em g/100 g de dieta em "base seca". A energia metabolizável foi calculada a partir dos dados de composição centesimal, Resolução $n^{\circ} 63$ [7]. No cálculo foram usados os fatores de conversão de $4 \mathrm{kcal}$ para carboidrato e proteína e de 9 kcal para lipídios.

\section{4 - Avaliação de lisina disponível e digestibilidade in vitro de proteínas}

A análise da lisina disponível foi feita após o preparo, congelamento e liofilização das amostras. Foi utilizado o método de KAKADA, LIENER [8]. Nessa reação os grupos $\alpha$ e $\varepsilon-\mathrm{NH}_{2}$ livres reagem com o ácido 2,4,6-trinitrobenzenosulfônico, formando como produto o derivado trinitrofenil que pode ser quantificado por espectrofotometria a $346 \mathrm{~nm}$ (Spectrophotometer, DU 70, Beckman ${ }^{\circledR}$, Corona, USA). A avaliação individual da lisina, muito suscetível a perdas durante o processamento, é um indicador importante do valor nutricional das proteínas.

A digestibilidade da proteína deve ser entendida como sendo a porção da proteína que pode ser hidrolisada pelas enzimas digestivas até aminoácidos e que, portanto, estaria disponível biologicamente, desde que não houvesse nenhuma interferência na absorção dos aminoácidos pelo organismo humano. A digestibilidade das proteínas foi determinada pelo método de AKESON, STAHMAN [1], que é a avaliação in vitro através da determinação da taxa de hidrólise por associações enzimáticas de pepsina e pancreatina, simulando as condições existentes no trato gastrintestinal (centrífuga Sorval ${ }^{\circledR}, \mathrm{RC}-5 \mathrm{C}$, Corona, USA; banho metabólico com agitação reciprocante, M-093, tipo Dubnoff, Marconi ${ }^{\circledR}$, Piracicaba, Brasil).

\section{3 - RESULTADOS E DISCUSSÃO}

\section{1 - Composição centesimal}

Os resultados das análises da composição centesimal estão demonstrados nas Tabelas 2 e 3.

TABELA 2 - Composição centesimal (\% base seca) das formulações (F1 e F2)

\begin{tabular}{lcc}
\hline Composição (\%) & ${ }^{\mathrm{a}} \mathbf{F 1}$ & ${ }^{\mathrm{a}} \mathbf{F 2}$ \\
\hline Calorias & 454,69 & 463,92 \\
Umidade $^{\mathrm{b}}$ & $79,29 \pm 0,07$ & $78,96 \pm 0,09$ \\
${\text { Proteína bruta }(\mathrm{Nx} 6,25)^{\mathrm{b}}}$ & $17,04 \pm 0,06$ & $16,56 \pm 0,09$ \\
Lipídios totais $^{\mathrm{b}}$ & $14,85 \pm 0,11$ & $15,12 \pm 0,20$ \\
Carboidratos $^{\mathrm{c}}$ & 63,22 & 65,40 \\
Fibra alimentar solúvel $^{\mathrm{b}}$ & $0,67 \pm 0,66$ & $1,09 \pm 0,11$ \\
Fibra alimentar insolúvel $^{\mathrm{b}}$ & $1,65 \pm 0,73$ & $1,84 \pm 0,09$ \\
Fibra alimentar total $^{\mathrm{b}}$ & 2,32 & 2,92 \\
Cinzas & $2,57 \pm 0,01$ & $2,6 \pm 0,08$ \\
\hline
\end{tabular}

${ }^{\mathrm{a}} \mathrm{F} 1 \mathrm{e}^{\mathrm{a}} \mathrm{F} 2[2]$

${ }^{b}$ Média de três determinações em duplicatas \pm desvio-padrão

'Calculado por diferença [100-(proteína+lipídio+umidade+cinza+fibra alimentar total)]

Nos dois casos, a distribuição do valor calórico total dos macronutrientes estava adequada com os parâmetros da literatura [5], com os seguintes percentuais: F1 15\% de proteína, 29\% de gordura e 56\% de carboidrato; F2 15\% de proteína, $29 \%$ de gordura e $55 \%$ de carboidratos, proporcionando, assim maior confiabilidade no valor nutricional das dietas e mais segurança na utilização e demonstrando a 
importância da padronização determinada cientificamente para evitar variação do valor nutricional.

TABELA 3 - Composição centesimal (\% base úmida) das formulações (F1 e F2)

\begin{tabular}{lcc}
\hline Composição (\%) & ${ }^{\text {aF1 }}$ & a F2 \\
\hline Calorias & 94,16 & 97,60 \\
Umidade & 79,29 & 78,96 \\
Proteína bruta & 3,53 & 3,48 \\
Lipídios totais $^{\text {Carboidratos }}{ }^{\mathrm{b}}$ & 3,07 & 3,18 \\
Fibra alimentar solúvel $_{\text {Fibra alimentar insolúvel }}$ & 13,10 & 13,76 \\
Cinzas & 0,14 & 0,22 \\
\hline
\end{tabular}

${ }^{\mathrm{a} F 1}$ e ${ }^{\mathrm{a}} \mathrm{F} 2$ [2]; ${ }^{\mathrm{b}}$ calculado por diferença

[100-(proteína+lipídio+umidade+cinza+fibra alimentar total)]

\section{2 - Teores de lisina disponíveis de proteínas}

A Figura 1 mostra os teores de lisina disponíveis de proteínas das formulações (F1 e F2). A lisina, um aminoácido essencial, é considerado como um indicador do valor biológico das proteínas. O teor de lisina, porém, nem sempre se correlaciona bem com o valor nutricional, porque parte dos grupos $\alpha$ e $\varepsilon-\mathrm{NH}_{2}$ livres podem ter reagido com compostos naturais como os açúcares redutores em produtos processados termicamente, ou os aldeídos provenientes da auto-oxidação de gorduras, durante o processamento ou estocagem. Por essa razão, é mais relevante determinar o teor de lisina disponível ou biologicamente ativo.

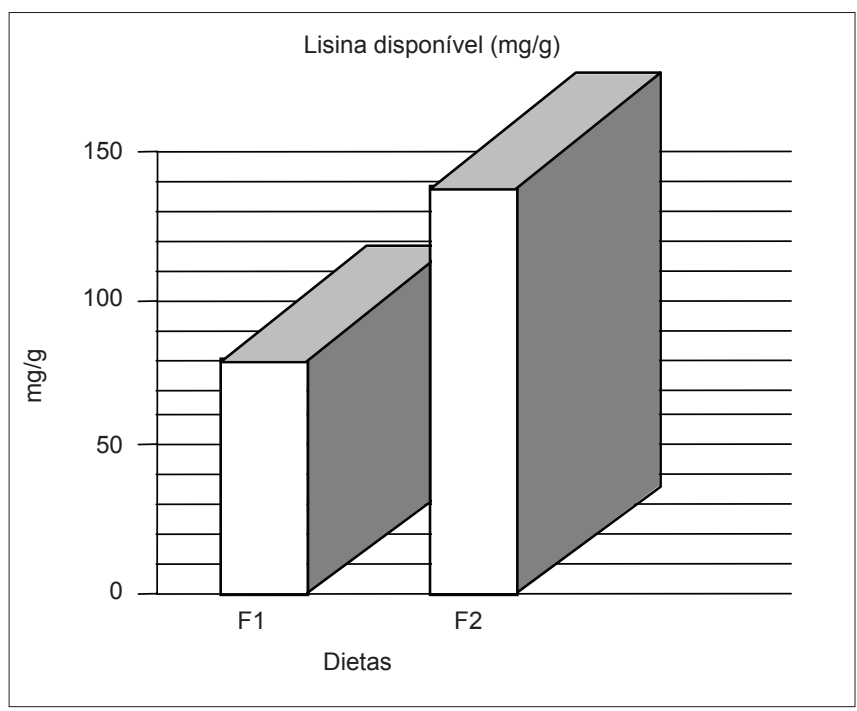

FIGURA 1 - Teores de lisina disponível (mg/g de proteína) de formulações (F1 e F2)

Os resultados demonstram que os teores de lisina se encontram dentro dos padrões [11], em quantidades de $80 \mathrm{mg} / \mathrm{g}$ e $139 \mathrm{mg} / \mathrm{g}$ de proteína para as formulações F1 e F2 respectivamente.

\section{3 - Percentuais de digestibilidade in vitro de proteínas}

A Figura 2 mostra os percentuais de digestibilidade in vitro de proteínas das formulações (F1 e F2). A determinação da digestibilidade é importante para avaliar o valor nutritivo da proteína. A Figura 2 mostra que não ocorreram ações ou interações de proteínas com outros componentes do alimento durante o processamento.

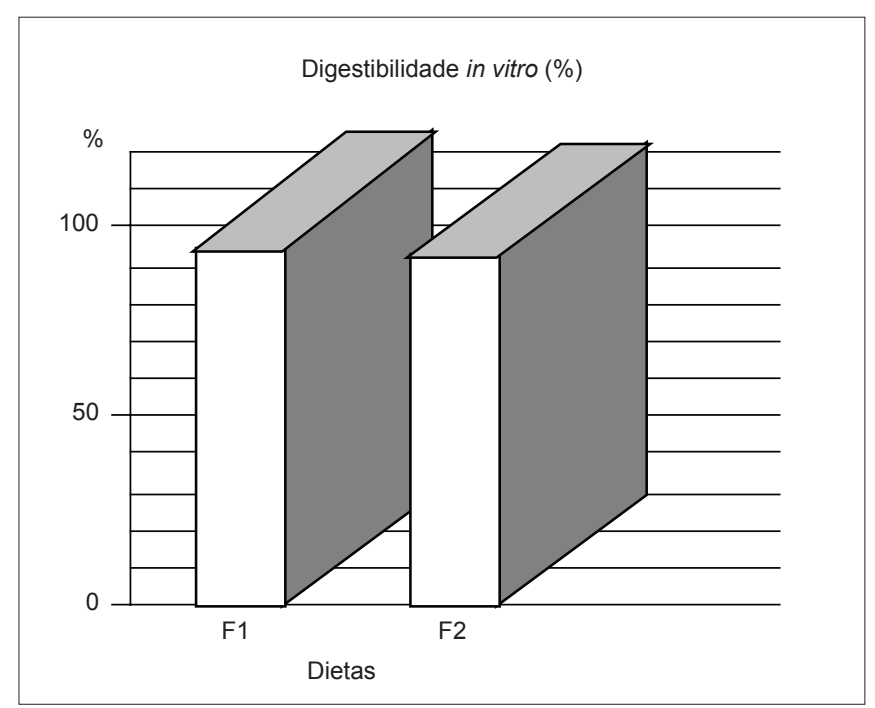

FIGURA 2 - Índice de digestibilidade (\%) in vitro de proteínas das formulações (F1 e F2)

Os percentuais de digestibilidade (Figura 1) mostram que as fórmulas F1 (95\%) e F2 (93\%) apresentaram digestibilidade elevada, aproximadamente igual a das proteínas de origem animal (acima de 95\%) [11], demonstrando assim que não ocorreu perda de digestibilidade no processamento.

Os resultados das análises de lisina disponível e de digestibilidade in vitro demonstram que as fórmulas $\mathrm{F} 1 \mathrm{e}$ F2 apresentam uma boa qualidade protéica.

\section{4 - CONCLUSÕES}

As formulações F1 e F2 possuem fonte protéica de boa qualidade e de baixo custo, podendo atender às necessidades nutricionais de indivíduos em terapia nutricional domiciliar e promover a recuperação ou manutenção do estado nutricional.

Nas fórmulas F1 e F2, a distribuição percentual do valor calórico total ficou equilibrada.

\section{5 - REFERÊNCIAS BIBLIOGRÁFICAS}

[1] AKESON, W.R.; STAHMAN, M.A.A. Pepsin pancreatin digest index of protein quality evaluation. J. Nutr., Bethesda, v. 83, n. 1, p. 257-261, 1964.

[2] ARAÚJO, E.M.; GALEAZZI, M.A.M. Inventores: Fórmulas para Nutrição Enteral com Alimentos Convencionais. BR. N. PI 9905419-1. NEPA/UNICAMP. Campinas, 1999.

[3] ASP, N.G.; JOHANSSON, C.G.; HALLMER, H.; SILJESTÖM, M. Rapid enzymatic assay of insoluble and soluble dietary fiber. J. Agric. Food Chem., Washington, v. 31 n. 3, p. 476-482, 1983.

[4] ASSOCIATION OF OFFICIAL ANALYTICAL CHEMISTS. 
Official Methods of Analysis. $14^{\text {th }}$ ed., Washington DC, 1984, $1141 \mathrm{p}$.

[5] BAXTER, Y.C.; WAITZBERG, D.L.; RODRIGUES, J.J.G.; PINOTTI, H.W. Critérios de decisão na seleção de dietas enterais. In Waitzberg D.L (Ed). Nutrição Oral, Enteral e Parenteral na Prática Clínica. $3^{\mathrm{a}}$ ed. São Paulo: Atheneu, 2000. Cap. 41, p. 659-676.

[6] BLIGH, E.G.; DYER, W.J. A rapid method of total lipid extraction and purification. Can. J. Biochem. Physiol., v. 37, p. 911-917, 1959.

[7] BRASIL. Resolução ${ }^{\circ} 63$ de julho de 2000. Ministério da Saúde, Agência de Vigilância Sanitária, Brasília, DF.

[8] KAKADE, M.L.; LIENER, I.E. Determination of available lysine and proteins. J. Analyt Biochem., New York, v. 27, n. 2, p. 273-280, 1969.

[9] MINISTÉRIO DA SAÚDE, NÚCLEO DE ESTUDOS E PESQUISAS EM ALIMENTAÇÃO-NEPA/UNICAMP.
Tabela Brasileira de Composição de Alimentos. Versão 1. Campinas, 2004; disponível em $<$ http://www.unicamp.br/nepa/taco $>$. Acesso em: 20 set 2005.

[9] INSTITUTO ADOLFO LUTZ. Normas Analíticas. $3^{\text {a }}$ ed. 1985. São Paulo.

[10] SGARBIERI, V.C. Proteínas em Alimentos Protéicos. São Paulo: Livraria Varela 1996, cap. IV, p. 337-381.

[11] STEPHAN, A.B.; BRITO, S.; MONTONE, M. Perfil nutricional dos pacientes com terapia nutricional enteral em assistência domiciliar. Rev. Bras. Home Care, Rio de Janeiro, n. 93, p. 26-28, 2003.

[12] YAMAUTI, A.C.; ANDRADE, K.C.; CORDELINI, S.; PIASSA H.H.C.S. Nutrição em home care: importância da adaptação dietética à realidade domiciliar. Rev. Bra. Home Care. PRONEP. Rio de Janeiro, p. 51: 4-5, 1999. 